Institute of $\mathbf{F}_{\text {ood and }} \mathbf{A}_{\text {gricultural }} \mathbf{S}_{\text {ciences }}$

\title{
Manual de los Reglamentos del Agua de Florida: Reglamento Privado ${ }^{1}$
}

\author{
Michael T. Olexa, Laura Minton, Dulcy Miller, y Sarah Corbett ${ }^{2}$
}

\section{Agradecimientos}

Los autores agradecen a Richard Budell de la Oficina de Política del Agua Agrícola del Departamento de Agricultura y Servicios al Consumidor de Florida. Los autores también agradecen a David H. Hammonds, Consultor del Programa de Salud Ambiental, Oficina de Programas de Aguas de Drenaje en el Sitio, del Departamento de Salud de Florida, y a Edward A. Bettinger, Consultor del Programa de Salud Ambiental, Oficina de Programas de Agua del Departamento de Salud de Florida.

\section{Sinopsis}

Otra forma de reglamentar la calidad del agua es a través de juicios legales privados. Esos juicios legales están basados frecuentemente en los principios de perjuicio y negligencia de la ley. También, algunas leyes federales tienen cláusulas que permiten a los ciudadanos hacer cumplir esas leyes. Es importante entender como usted puede ser sujeto a responsabilidades por sus acciones, por otros miembros del publico.

\section{¿Qué es el Perjuicio?}

La teoría del perjuicio, es un principio común de la ley de litigación por contaminación, estipula que uno no puede usar sus propiedades de tal manera que cause daño a otros. Los perjuicios son

1. Este es el documento EDIS FE077, una publicación del Department of Food and Resource Economics, Florida Cooperative Extension Service, Institute of Food and Agricultural Sciences, University of Florida, Gainesville, FL. Publicada Noviembre 2002. Por favor visite la página electrónica EDIS en http://edis.ifas.ufl.edu.

2. Michael T. Olexa, es profesor del Department of Food and Resource Economics, Florida Cooperative Extension Service, Institute of Food and Agricultural Sciences, University of Florida, Gainesville, FL; y miembro de Florida Bar; Presidente de Agricultural Law Committee of The Florida Bar; y Director del Agricultural Law Center. Laura Minton, Dulcy Miller, y Sarah Corbett son estudiantes graduadas de Levin College of Law, University of Florida, Gainesville, FL. Filiberto Reyes-Villanueva fue el traductor de la versión en ingles al español.

Esta publicación esta diseñada para proporcionar información precisa, actualizada y autorizada sobre esta material. Sin embargo, ya que las leyes, reglas administrativas y decisiones de la corte, sobre las cuales están basados, están sujetas a revisión constante; algunas partes de esta publicación podrían ser obsoletas en cualquier momento. Esta publicación es distribuida bajo el entendimiento que los autores no están involucrados en ninguna representación legal u otros servicios profesionales, y que la información contenida aquí no debe ser considerada como un substituto de una asesoria legal. Esta publicación no esta completa en proporcionar toda la información para lograr el cumplimiento de las leyes y reglamentos que gobiernan la protección del agua. Por estas razones, el uso de estos manuales por cualquier persona constituye un acuerdo para mantener libre de daño a los autores, al Florida Cooperative Extension Service, al Institute of Food and Agricultural Sciences, y a la University of Florida por cualquier demanda por responsabilidad de daños, o gastos en que pueda incurrir cualquier persona, como un resultado de hacer referencia o confianza sobre la información contenida en esta publicación. Esta publicación fue apoyada financieramente por el Florida Department of Agriculture and Consumer Services.

El Instituto de Alimentos y Ciencias Agrícolas es Un empleador que opera bajo Acción Afirmativa y provee Oportunidades Igualitarias, dedicado a promocionar la investigación, a información educativa y otros servicios, únicamente a los individuos e instituciones que operan baj discriminación sin considerar color, raza, sexo, edad, incapacidad u origen. Para más información sobre como obtener otras publicaciones de la extensión, comuníquese con la oficina de Servicio de Extensión de su condado. Servicio de Extensión de la Florida / Instituto de Alimentos y Ciencias Agrícolas / Universidad de la Florida / Christine Taylor Waddill, Decana. 
clasificados como públicos o privados, dependiendo de si el perjuicio afecta los derechos del público o solamente los derechos de un individuo. Las acciones de perjuicio publico pueden ser conducidas por un funcionario público a nombre de un público en general; ciertos tipos de perjuicio público pueden ser además actos penales.

En las acciones de perjuicio, la corte hará frecuentes balances del valor social del perjuicio contra el daño que causa. Si el daño es ligero y el valor social es grande el juicio no procede. Pero si el valor social es pequeño y el daño es grande, el demandante puede recuperar el daño en términos económicos, como también lograr prohibir al acusado de continuar con sus actividades.

\section{¿Qué es el Acta del Derecho a Cultivar de Florida?}

El Acta del Derecho a Cultivar de Florida [Estatutos de Florida, Sección 823.14] restringe los juicios por perjuicio contra los agricultores, estipulando que ninguna granja, la cual no fue molestia cuando fue establecida, constituirá una molestia publica o privada después de un año de operación. Un cambio de propietario no afecta las disposiciones del Acta de Derecho a Cultivar de Florida. Además el Acta de Derecho a Cultivar de Florida estipula que los gobiernos locales no pueden adoptar ninguna regla u ordenanza la cual restringa o limite una actividad agrícola de buena fe, que este conducida en tierras agrícolas de acuerdo mediante las prácticas del mejor manejo.

Esto no da al agricultor permiso para violar los principios legales de negligencia o perjuicio. Contaminar un pozo de agua o un mal uso de plaguicidas podrían exponer al agricultor a un juicio potencial. El Acta del derecho a Cultivar de Florida no extiende protección para condiciones insalubres, daños a la salud o cambios de uso, ya sea en tipo o intensidad.

\section{¿Qué es Negligencia?}

Negligencia es causar daño a alguien, por fallar al hacer lo que una persona razonablemente haría bajo las mismas circunstancias. El daño puede ser económico, físico o emocional. Cualquiera que busca recuperarse por la negligencia de alguien, debe probar cuatro elementos legales: deber, violación del deber, causa del daño y valor del daño.

\section{Deber}

Es una responsabilidad individual para gobernar su propia conducta de tal manera que otros no sean dañados.

\section{Violación del Deber}

La violación del deber ocurre donde una de las partes no cumple su deber con cuidado. Esto es que la persona no actúa con el grado de precaución o prevención que una persona responsablemente prudente debería haber hecho en la misma situación.

\section{Causa}

La causa ocurre cuando la falla del acusado al no usar el debido cuidado, causa daño al demandante. La prueba de este paso puede ser difícil si el daño es solamente indirecto respecto a los actos del demandante, o si hay otras causas posibles para el daño.

\section{Efecto Causal}

Cuando la falla del ofensor por no usar el debido cuidado, causo daño al demandante. Probar esto es difícil si el daño solo esta indirectamente relacionado con el acto del ofensor, o si hay otras causas posibles de daño.

\section{Daño}

El demandante debe probar que sufrió daño real por los actos del acusado. Si no resultó un daño, aún donde la conducta del acusado fue admitida como negligente, el demandante no puede reclamar por negligencia.

\section{¿Qué es Negligencia Per Se?}

Cuando los actos de un acusado lo exponen a un juicio privado, y al mismo tiempo, viola un estatuto, la corte generalmente considerará la violación del estatuto como evidencia suficiente de injusta conducta para encontrar al acusado culpable de negligencia, así como en el juicio privado también. 
Sin embargo esta regla se aplica solamente si existen dos condiciones. Primero, el daño reclamado en el juicio debe ser del tipo que el estatuto intenta prevenir. Segundo, el demandante debe ser un miembro de la clase de personas que el estatuto pretende proteger.

Debe aclararse que el cumplimiento de todos los estatutos no garantiza inmunidad para las acciones de negligencia, así como el comportamiento licito aun puede ser negligente.

\section{¿Qué es la Responsabilidad Estricta?}

La responsabilidad estricta es la responsabilidad impuesta sin evidencia de negligencia. Esto es, el acusado puede ser encontrado culpable con una demostración de que su acción resulto en daño, sin considerar si actuó responsablemente o no. La responsabilidad estricta o "ultra peligrosas" (como el manejo de explosivos) u otras actividades definidas por estatuto (como el ARCRAC).

\section{¿Qué es una Responsabilidad Conjunta y por Separado?}

Donde dos o mas partes, actuando independientemente, son la fuente de daños para el demandante, la ley (o las cortes) pueden imponer el principio de responsabilidad conjunta o por separado. Este principio permite al demandante recuperar de cualquier acusado la cantidad completa de su daño, y obliga a los acusados a reparar la perdida poniendo cada uno la parte que le corresponde. 